\title{
Steel fibre-reinforced concrete: Multi-scale characterisation towards numerical modelling
}

\author{
Stephan Zeranka ${ }^{1, *}$ and Gideon van Zij $1^{1}$ \\ ${ }^{1}$ Stellenbosch University, Department of Civil Engineering, Stellenbosch, South Africa
}

\begin{abstract}
The Mode I and II fracture response of steel fibre-reinforced concrete is investigated experimentally at the single fibre and composite scale. A constitutive material model is developed and is implemented in a numerical procedure via a user material (UMAT) in the commercial finite element package ABAQUS. An empirical model reconciles the single fibre and composite scale for Mode II fracture.
\end{abstract}

\section{Introduction}

Limited research has been done on the direct shear behaviour of fibre reinforced concrete. Even fewer investigations attempt to reconcile the single fibre scale (i.e. transverse fibre pull-out) with the composite scale. To the authors' knowledge only two studies $[1,2]$ have applied this method for characterising the direct shear fracture of Steel Fibre Reinforced Concrete (SFRC).

The outcome of an investigation conducted by the authors [3] into multi-scale characterisation towards constitutive and numerical modelling, in sequence are: Adapt a composite design procedure and develop a SFRC; Classify the composite in terms of standard performance indicators and testing procedures; Design, fabricate and execute experimental tests to characterise the Mode I and Mode II fracture at the single fibre and composite-scale; Develop a material model and verify it numerically: This requires the implementation of an analytical formulation of the material model into a numerical procedure. The material model is calibrated with the experimental data and verified via a Finite Element (FE) representation of the experimental composite-scale test. Finally, an empirical model is also developed which reconciles the fibre component with the composite response.

Two useful technologies are utilised to assist in material characterisation, Computed Tomography (CTscan) and Digital Image Correlation (DIC). The CTscanning facility provides valuable insight into the fibre distribution and the ability to analyse and quantify the fibre orientation distribution is a powerful tool. The noncontact measurement method (Aramis DIC) proved invaluable in determining the specimen shear displacement and rotation.

\section{Experimental investigation of Mode I fracture}

The Mode I or uniaxial tensile fracture is investigated experimentally. The first subsection considers the composite behaviour i.e. within the vicinity of a single, well-defined, localised crack. The second section considers the axial pull-out response of the embedded fibre. The specimen design, experimental program, production method, test setup, procedure and results are discussed.

\subsection{Composite scale}

\subsubsection{Specimen design}

A range of geometric parameters are investigated, including: gauge width $\left(w_{g}\right)$, end width $\left(w_{e}\right)$, thickness $(t)$, gauge length $\left(l_{g}\right)$, transition length $\left(l_{t}\right)$ and transition radius ( $r$ ) (Fig.1a). Numerical analyses are performed in the elastic domain to refine specimen geometry. The final geometry is shown in Fig.1b. Modifications to the specimen are necessary to achieve localised failure in the gauge zone, namely reinforcement in the transition zone to prevent premature failure and a $4.5 \pm 0.5 \mathrm{~mm}$ saw-cut notch in the middle of the specimen on both short sides.

\subsubsection{Experimental program and production method}

Research parameters (Table 1) include fibre volume and composite type i.e. Self-Consolidating Concrete (SCC) or Self-Consolidating Mortar (SCM). There are 8 test series with 6 specimens each, totalling 48 specimens.

* Corresponding author: szeranka@sun.ac.za 
Table 2. Summary of uniaxial tension test data

\begin{tabular}{|c|c|c|c|c|c|c|c|c|c|}
\hline & & & SCM & & & SCC & & & \\
\hline$V_{f}$ & [\%] & $0^{*}$ & 0.5 & 0.75 & 1.0 & 0 & 0.5 & 0.75 & 1.0 \\
\hline $\mathrm{w}_{\mathrm{m}}$ & {$[\mu \mathrm{m}]$} & 7.4 & 6.0 & 6.4 & 6.0 & - & 6.9 & 6.2 & 6.3 \\
\hline C.V. & [\%] & 11.8 & 29.4 & - & 39.3 & - & 8.8 & 16.0 & 29.3 \\
\hline$\sigma_{t, m}$ & [MPa] & 3.56 & 2.85 & 2.99 & 2.61 & 3.12 & 4.40 & 3.40 & 3.65 \\
\hline C.V. & [\%] & 7.7 & 30.8 & - & 38.8 & 18.5 & 5.1 & 24.8 & 17.1 \\
\hline $\mathrm{N}_{\mathrm{f}}$ & {$[-]$} & - & 35 & 52 & 59 & - & 25 & 45 & 63 \\
\hline C.V. & [\%] & - & 14 & 17 & 22 & - & 22 & 18 & 13 \\
\hline $\mathrm{G}_{\mathrm{f}}^{0.1 \mathrm{~mm}}$ & {$[\mathrm{~N} / \mathrm{mm}]$} & - & 0.22 & 0.23 & 0.22 & - & 0.31 & 0.26 & 0.32 \\
\hline $\mathrm{G}_{\mathrm{f}}^{0.3 \mathrm{~mm}}$ & {$[\mathrm{~N} / \mathrm{mm}]$} & $\begin{array}{ll}- & -1 \\
-1\end{array}$ & 0.61 & 0.72 & 0.72 & - & 0.74 & 0.65 & 0.93 \\
\hline$\overline{\mathrm{G}_{\mathrm{f}}^{1.0 m m}}$ & {$[\mathrm{~N} / \mathrm{mm}]$} & - & 2.05 & 2.34 & 2.30 & - & 1.58 & 1.89 & 2.54 \\
\hline$\overline{\mathrm{G}_{\mathrm{f}}^{2} .0 \mathrm{~mm}}$ & {$[\mathrm{~N} / \mathrm{mm}]$} & - & 3.23 & 3.79 & 3.51 & - & 2.11 & 2.75 & 3.55 \\
\hline $\begin{array}{l}\text { C.V. } \\
\left(\mathrm{G}_{\mathrm{f}}^{2.0 \mathrm{~mm}}\right)\end{array}$ & [\%] & - & 10.8 & 21.7 & 20.6 & - & 18.6 & 19.6 & 14.4 \\
\hline
\end{tabular}

* Specimens were not notched

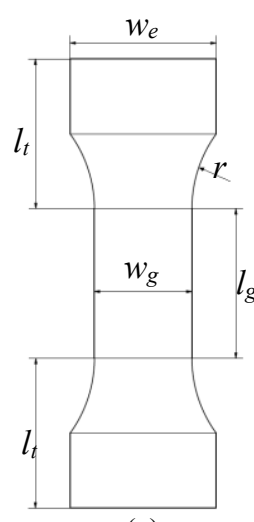

(a)

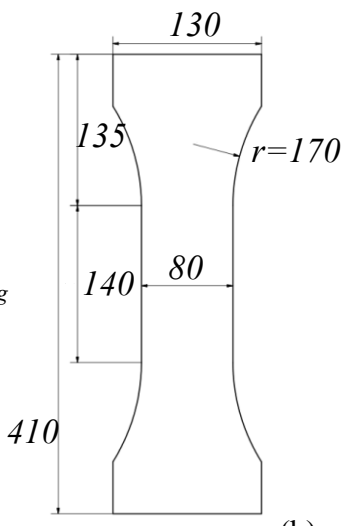

(b)

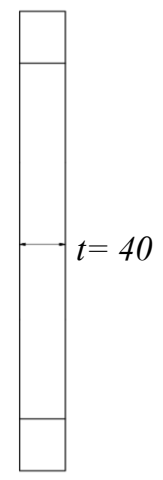

Fig. 1. (a) Specimen parameters and (b) final geometry

Table 1. Research parameters and values for uniaxial tension

\begin{tabular}{ll}
\hline Research parameter & Parameter values: \\
\hline Fibre volume fraction, $\mathrm{V}_{\mathrm{f}}$ & $\begin{array}{l}0 \%, 0.5 \% .0 .75 \% \& 1.0 \% \text { of } \\
\text { mortar/concrete volume }\end{array}$ \\
\hline Fibre type & $\begin{array}{l}\text { RC- } 65 / 35-\mathrm{BN}\left(\mathrm{L}_{\mathrm{f}} \approx 35 \mathrm{~mm}, \mathrm{~L}_{\mathrm{f}} / \mathrm{d}_{\mathrm{f}} \approx 65,\right. \\
\text { Low carbon, Hooked-end) }\end{array}$ \\
\hline $\begin{array}{l}\text { Average aggregate } \\
\text { particle size, } a\end{array}$ & $\begin{array}{l}<4.75 \mathrm{~mm}(\mathrm{mortar} / \mathrm{no} \text { coarse } \\
\text { Hogregate) and } 9.5 \mathrm{~mm}(\mathrm{Greywacke}\end{array}$ \\
\hline $\begin{array}{l}\text { Coarse aggregate content, } \\
\mathrm{V}_{\mathrm{a}}\end{array}$ & $\begin{array}{l}0 \mathrm{~kg} / \mathrm{m}^{3} \text { (mortar) and } 450 \mathrm{~kg} / \mathrm{m}^{3} \text { of } \\
\text { concrete volume }\end{array}$ \\
\hline
\end{tabular}

Note: Sample size $=6$

\subsubsection{Test setup and procedure}

A Zwick Z250 testing machine is used for all tests. The test configuration and instrumentation is shown in Fig.2a\&b. Hydraulic-pneumatic clamps provide a non- rotatable boundary condition. An extensometer records specimen deformation on both sides. The test rate is controlled by the machine crosshead position at 0.15 $\mathrm{mm} / \mathrm{min}$ until a maximum extensometer reading of 2 $\mathrm{mm}$. Fig.2c shows typical specimen failure.

\subsubsection{Test results and discussion}

Table 2 includes the matrix cracking strength $\left(w_{m}, \sigma_{t, m}\right)$, fibre count $\left(N_{f}\right)$ and specific fracture energy $\left(G_{f}\right)$. The coefficient of variation (C.V.) is also given. Fig. 3 plots the combined average response for SCM and SCC for each fibre dosage and average response of all test samples combined.

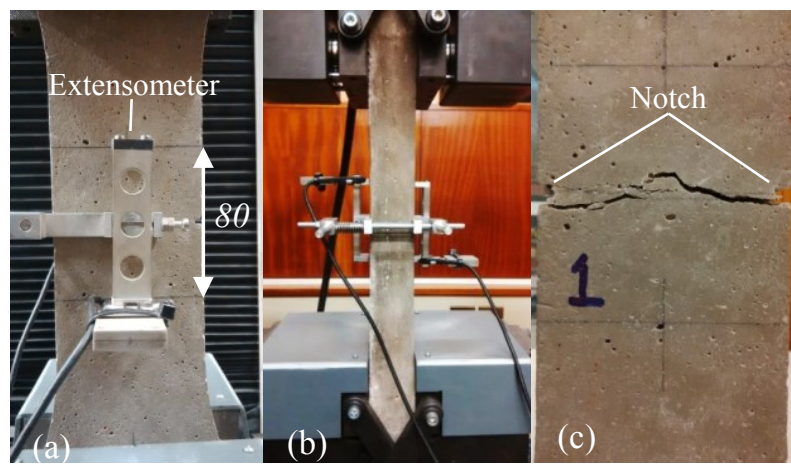

Fig. 2. (a\&b) Test configuration and instrumentation and (c) example of a failed specimen.

\subsection{Single fibre scale}

This subsection reports on the axial pull-out of steel fibre $R C-65 / 35-B N$ [4] embedded in SCM. 


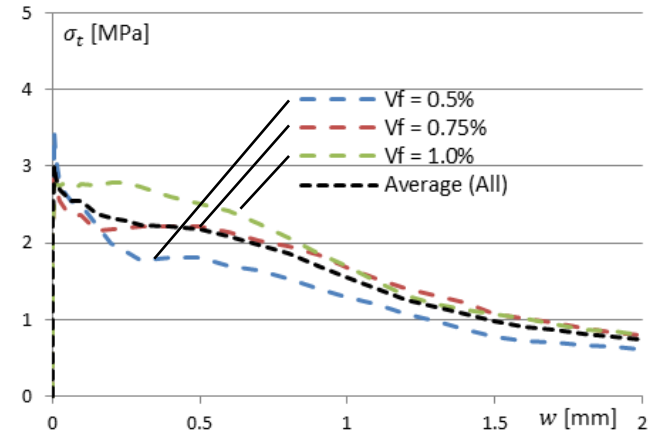

Fig. 3. Average tensile response (combined SCM \& SCC)

\subsubsection{Experimental program and production method}

Important parameters include the fibre material, fibre geometry, fibre embedded length $\left(\mathrm{L}_{\mathrm{fe}}\right)$, fibre inclination $(\theta)$ and matrix properties. Parameters investigated in this study include end anchorage (with and without), $\mathrm{L}_{\mathrm{fe}}=$ $\mathrm{L}_{\mathrm{f}} / 4, \theta=0^{\circ}, 30^{\circ}$ and $60^{\circ}$, as defined in Fig. 4. A total of 45 specimens are tested.

Each fibre is wedged between two wooden blocks in order to position the fibre at the required embedded length and inclination. Specimens are stored at room temperature $\left(24 \pm 2^{\circ} \mathrm{C}\right)$ and humidity $(50 \pm 5 \%)$ for 28 days.

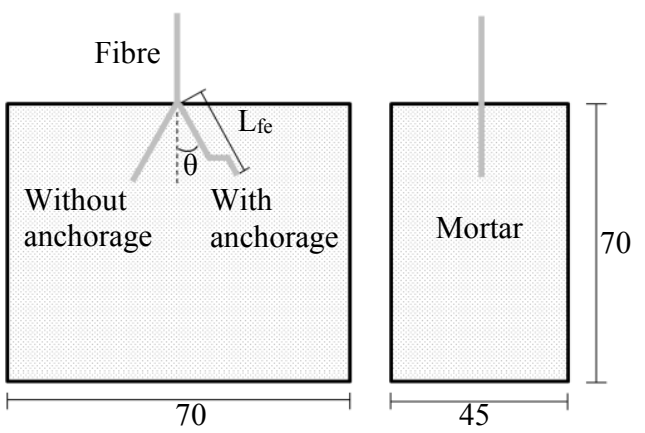

Fig. 4. Specimen dimensions (in $[\mathrm{mm}]$ ) and definition of fibre embedded length $\mathrm{L}_{\mathrm{fe}}$ and inclination angle $\theta$

\subsubsection{Test setup and procedure}

The test configuration is shown in Fig.5. The same machine and grips in the composite study are used. A load cell records fibre pull-out load and two Linear Variable Displacement Transducers (LVDTs) record fibre pull-out displacement. The fibre-end is clamped with a set screw (Fig.5b). A test rate of $0.015 \mathrm{~mm} / \mathrm{s}$ of the machine crosshead position is applied until complete fibre pull-out.

\subsubsection{Test results and discussion}

Increasing fibre inclination from $0^{\circ}$ to $30^{\circ}$ marginally increases peak and residual pull-out resistance (Fig.6a), but a $60^{\circ}$ inclination drastically reduces pull-out resistance. This is attributed to spalling failure of mortar immediately surrounding the fibre, causing fibre bond and anchorage to contribute less. In Fig.6b, the effect of fibre inclination is more prominent for a fibre without end-anchorage. Comparison of Fig.6a and Fig.6b shows that the anchorage mechanism dominates pull-out behaviour, but at larger inclinations, for the given fibre geometry and embedded length, end anchorage promotes spalling. A more detailed study should characterise the effect of fibre inclination, end-anchorage and 3D orientation of end-anchorage on the spalling effect.
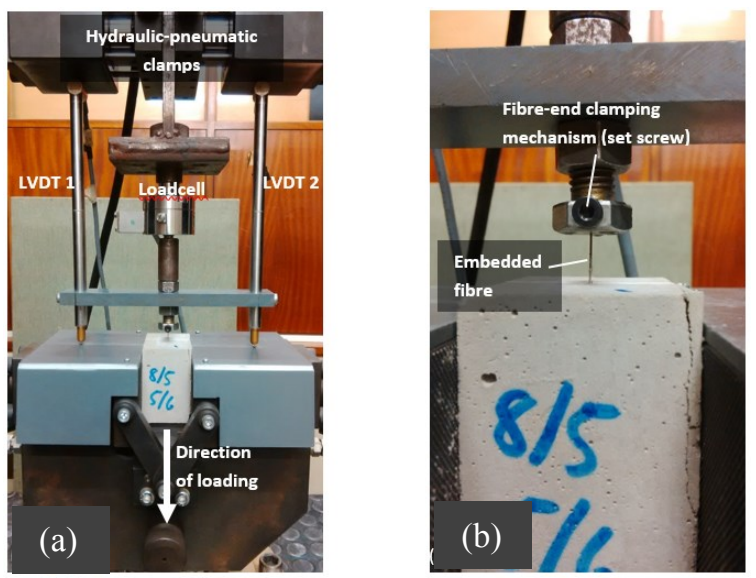

Fig. 5. (a) Test configuration and (b) fibre clamping mechanism

\subsection{Summary and conclusions}

On the composite scale, numerical refinement in the elastic domain gives some insight into the effect of geometric parameters on stress distribution. It is however less successful in producing a specimen geometry with reliable failure in the gauge zone. The specimen had to be reinforced and notched to ensure failure in the gauge zone. More experimental trials are needed with different geometries and materials.

The single fibre test setup and procedure provides repeatable data. The $R C-65 / 35-B N$ fibre is susceptible to corrosion during fully-submerged water-curing. A neutral curing method, with no loss or gain of moisture is recommended, should prevent corrosion and is more representative of in-situ curing.

\section{Experimental investigation of Mode II fracture}

The Iosipescu [5] shear test method is adapted via finite element refinement in the elastic domain, to investigate the composite shear behaviour of the fibre-reinforced SCM and SCC. The fibre distribution including the fibre count, orientation and embedded length is analysed for a number of tested specimens, via X-ray CT-scanning [3]. An experimental investigation is also performed in order to characterise the transverse pull-out response of the hooked-end steel fibre embedded in the SCM. 

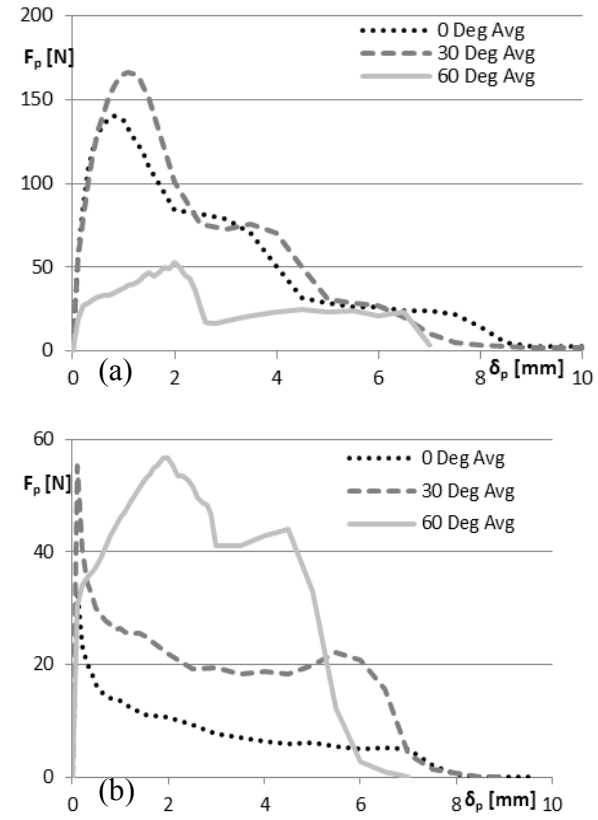

Fig. 6. Avg. fibre pull-out load $F_{p}[\mathrm{~N}]$ vs. pull-out displacement $\delta_{p}[\mathrm{~mm}]$ (a) with anchorage and (b) without anchrage.

\subsection{Composite scale}

\subsubsection{Specimen design}

The basic test configuration is shown in Fig.7a. Simple beam mechanics and numerical/FE refinement in the elastic domain is used to optimise specimen geometry. Two criteria need to be satisfied, namely for failure to occur in the shear plane and to achieve a uniform shear stress distribution in the shear plane. Possible failure modes include: (1) shear-dominant failure in the shear plane at the location of zero bending moment, (2) flexure-dominant failure at the location of maximum bending moment or (3) shear-flexure failure between the position of maximum flexure and the shear plane.

Restrictions with respect to testing equipment, the consideration of a representative fibre volume and production method determine overall dimensions. Numerical refinement in the elastic domain is used to optimise notch geometry. Parameters varied in the analysis include the notch angle $(\theta)$, notch tip radius $(r)$ and notch depth $(d)$ (Fig.7b), with final values $r=2.5$ $\mathrm{mm}, \theta=85^{\circ}$ and $d=12.5 \mathrm{~mm}$.
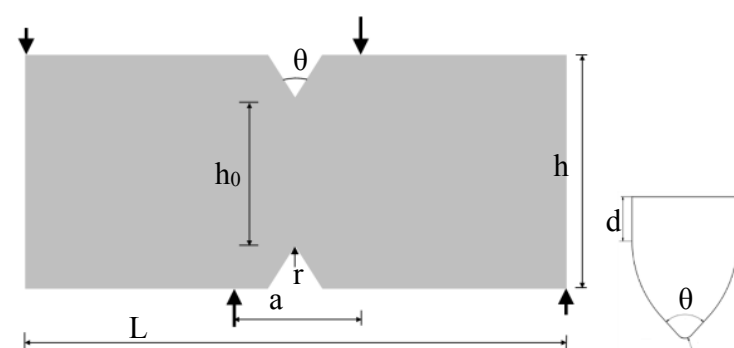

(b) $\mathrm{r}$

(a)

Fig. 7. (a) Basic test configuration and (b) notch geometry

\subsubsection{Experimental program and production method}

In total, 84 specimens are cast including three composite types: SCM, SCC-450 and SCC-600 [3]; three fibre volumes $V_{f}=0.5,0.75$ and $1.0 \%$ and two initial crack widths, $w_{i}=0.1 \mathrm{~mm}$ and $w_{i}=0.3 \mathrm{~mm}$.

Preliminary tests showed that specimens do not reliably fail in the shear plane. Compression splitting failure occurs at the points of load application, causing diagonal cracking between the two inner supports. The shear plane is therefore weakened with a $\sim 2.5 \mathrm{~mm}$ sawcut notch on both sides of the shear plane (Fig.8), which proved to be effective in localising the crack in the shear plane.

\subsubsection{Test setup and procedure}

The test procedure is divided into three phases:

Phase I - Cyclic tensile loading: Using the same clamping and instrumentation as for uniaxial tension. Each specimen subjected to 20 cycles of loading and complete unloading, with a displacement (extensometer) increment of $0.025 \mathrm{~mm}$. Test rate controlled by machine crosshead position at $0.25 \mathrm{~mm} / \mathrm{min}$. Maximum extensormeter displacement of $0.50 \mathrm{~mm}$. Average maximum crack width for target residual (unloaded) crack width determined from data.

Phase II - Pre-cracking: Same test setup as for Phase I. Specimens loaded to maximum crack width and then unloaded to achieve target residual crack width $\left(w_{i}\right.$ $=0.1 \mathrm{~mm}$ or $0.3 \mathrm{~mm})$. Test rate controlled at 0.05 $\mathrm{mm} / \mathrm{min}$ of machine crosshead position.

Phase III - Iosipescu shear test (Fig.8a): The specimen is centred with respect to the shear plane, with anti-symmetric inner load separation of $70 \mathrm{~mm}$ and outer support separation of $200 \mathrm{~mm}$. The test rate is controlled with the machine crosshead position at $0.3 \mathrm{~mm} / \mathrm{min}$ (until $3 \mathrm{~mm}$ displacement) and then $0.5 \mathrm{~mm} / \mathrm{min}$ until a crosshead displacement of $5 \mathrm{~mm} .12$ points arranged in four columns ( 2 columns on each side of the shear plane) and 3 rows over the height of the shear plane are monitored by the DIC system (Fig.8a). The 'stage' points are centred and equidistant with respect to the shear plane and measure the rotation over the height of the shear plane as well as the displacement parallel and normal to the rotating shear plane. The correct shear load component, which is also a function of the specimen rotation, is determined.

\subsubsection{Test results and discussion}

The results of Phase I, II and III will not be discussed here and can be found in [3]. Only a limited data set of Phase III will be analysed in the following section as verification of the constitutive model developed. 


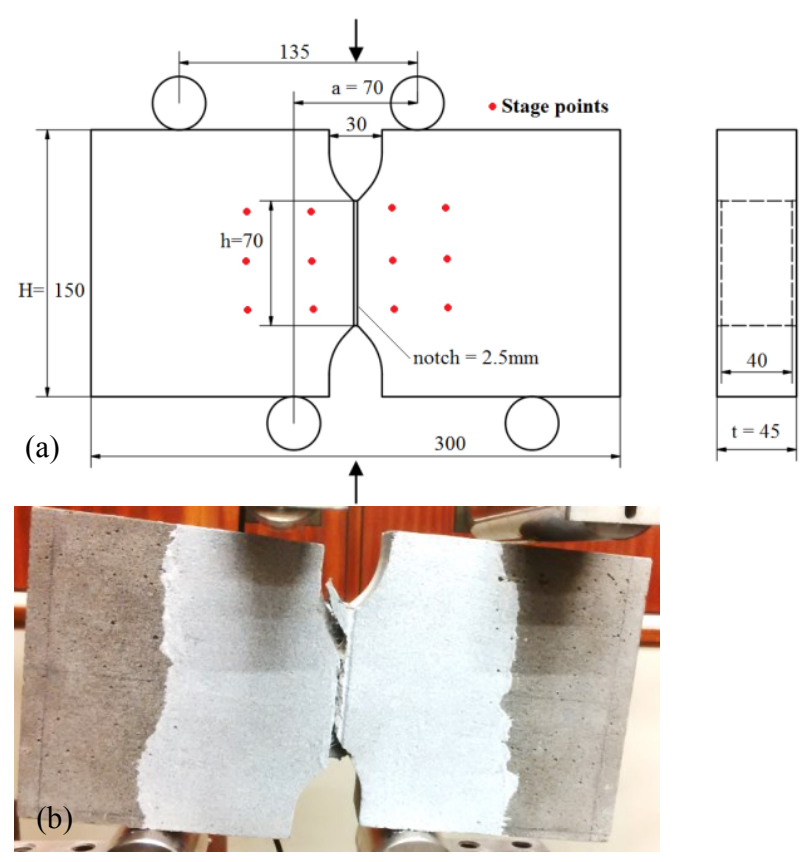

Fig. 8. (a) Test configuration showing load application and stage points used for DIC (b) fractured specimen.

\subsubsection{Analysis of fibre distribution via CT-scan}

The fibre count and orientation distribution is determined by analysing via X-ray CT-scanning, the number of fibres intersecting plane S3 (Fig.9). The CTscan and manual fibre count show similar values in most cases. The fibre orientation distribution $\left(0-90^{\circ}\right)$ relative to the longitudinal $\mathrm{z}$-axis is determined for two section volumes on either side of the shear plane (Fig.9). Note: CT-scans are performed on tested specimens, fibres are therefore deformed in the vicinity of the shear plane and this region should not form part of orientation analysis. Six orientation intervals are used to plot the distribution in Fig. 10.

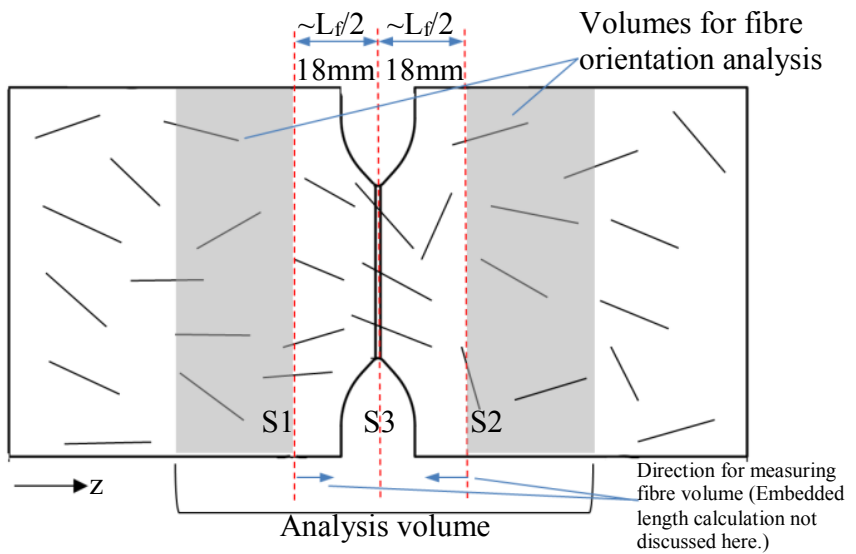

Fig. 9. CT-scan analysis and data extraction method

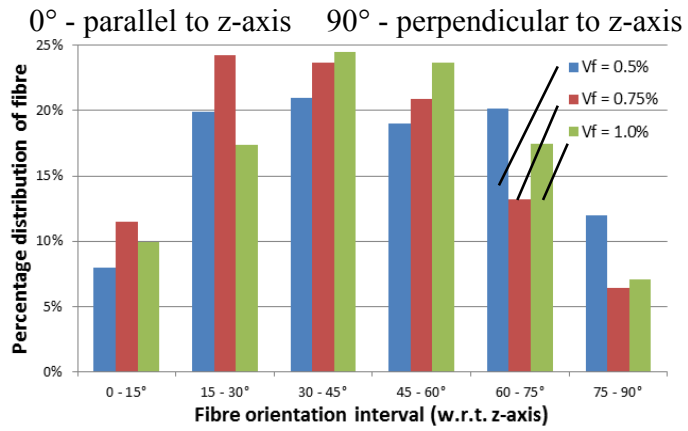

Fig. 10. Fibre orientation distribution $\left(\mathrm{SCC}-450, V_{f}=0.5\right.$ $1.0 \%)$

\subsection{Single fibre scale}

\subsubsection{Experimental program, specimen design and production method}

The Ohno-beam [6] shear test method is used to investigate the transverse pull-out of a single hooked-end steel fibre. Five fibre inclinations as defined in Fig. $11 \mathrm{~b}$ and two fibre embedded lengths, $L_{f} / 2$ and $L_{f} / 4$ are investigated. Specimen dimensions are given in Fig.11a. Specimen casting consists of two stages. First the fibre is wedged between two wooden blocks at the fibre inclination and embedded length and placed inside the mould. SCM is poured into half of the mould with the protruding fibre and allowed to harden at temperature $24 \pm 2{ }^{\circ} \mathrm{C}$ and $65 \pm 2 \%$ RH. Specimens are demoulded after 24 hours with the fibre fixed in position by the hardened mortar. The two halves of the specimen may not bond and therefore grease is applied to the shear plane surface of the specimen. Mortar is then poured into the second half of the mould and the specimen is again allowed to harden over 24 hours. Specimens are then water-cured for 28 days at $24 \pm 2^{\circ} \mathrm{C}$. Before testing, specimens are prepared for optical measurement similar to the composite scale test.

\subsubsection{Test setup and procedure}

The test setup is shown in Fig.11a. The specimen is centred with respect to the shear plane, with antisymmetric inner load separation of $30 \mathrm{~mm}$ and outer support separation of $110 \mathrm{~mm}$. The speed of the test is controlled with the machine crosshead position at 0.15 $\mathrm{mm} / \mathrm{min}$ until a crosshead displacement of $3 \mathrm{~mm}$, at which point the speed is increased to $0.6 \mathrm{~mm} / \mathrm{min}$ until fibre pull-out or rupture.

\subsubsection{Test results and discussion}

A summary of the average response for each orientation angle $\left(\theta=+60,+30,0,-30\right.$ and $\left.-60^{\circ}\right)$ and embedded length $L_{f} / 4$ is shown in Fig.12a (Transverse pull-out load, $F_{p t}[\mathrm{~N}]$ vs. transverse pull-out displacement, $\delta_{p t}$ $[\mathrm{mm}])$ and Fig.12b ( $F_{p t}$ Vs. normal pull-out displacement, $\left.\mathrm{n}_{\mathrm{pt}}[\mathrm{mm}]\right)$. Two failure modes are observed, fibre pullout or fibre rupture. In general the behaviour observed for the different fibre inclinations is similar to tests per- 

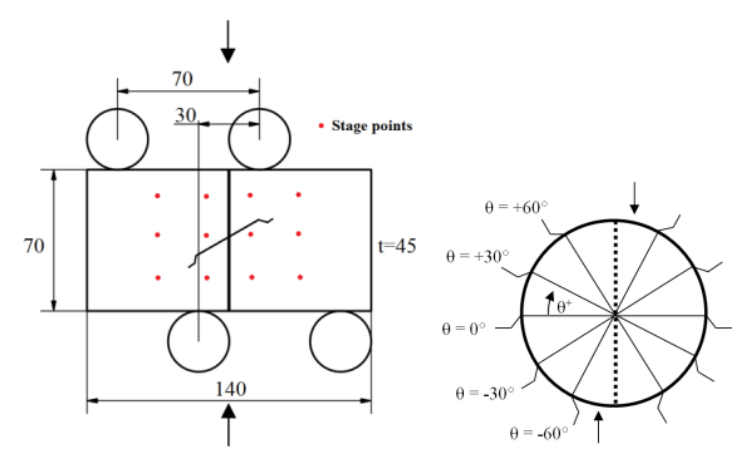

Fig. 11. (a) Test configuration and definition with respect to load direction

(b) fibre inclination

formed using the shear push-off [2] and shear pushthrough [1] methods. In summary, positive fibre inclinations $\left(\theta=+30^{\circ}\right.$ and $\left.+60^{\circ}\right)$ fail in pull-out only and negative inclinations $\left(\theta=-30^{\circ}\right.$ and $\left.-60^{\circ}\right)$ undergo substantial transverse displacement before the fibre is engaged. This is attributed to the snubbing effect. Fibre rupture in conjunction with snubbing or pull-out is the predominate mode of failure in this case. A fibre inclination in the region of $\theta=0^{\circ}$ represents a transition zone between fibre pull-out and fibre rupture and both failure modes are likely to occur. Lee \& Foster (2006) [2] provides a detailed explanation of this behaviour and the associated mechanisms.

\section{Constitutive model and numerical verification}

Abaqus [7] is a finite element program which provides an interface (UMAT) for connecting a user-defined constitutive model to its source code. The objective of this section is to develop a user-defined constitutive model that incorporates the composite-scale data. The constitutive model is verified by modelling the Iosipescu shear test. Finally, an empirical model reconciles the single fibre and composite scale data.
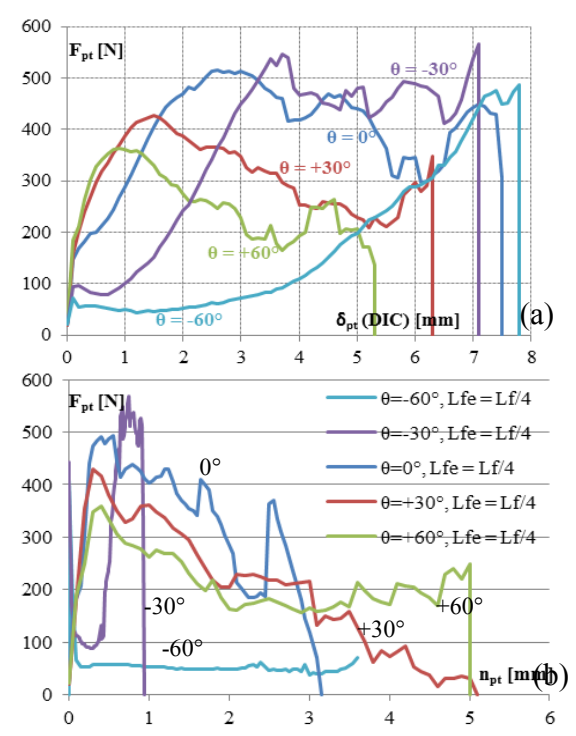

Fig. 12. (a) Transverse pull-out load $\left(F_{p t}\right)$ vs. transverse pullout displacement $\left(\delta_{\mathrm{pt}}\right)$ and (b) $\mathrm{F}_{\mathrm{pt}} \mathrm{vs.}$ normal pull-out displacement $\left(\mathrm{n}_{\mathrm{pt}}\right)$

\subsection{Modelling concept}

The smeared crack concept, originally proposed by Rashid (1968) [8] is used in this study. A cracked solid remains a continuum and the effect of the $\operatorname{crack}(\mathrm{s})$ is distributed or "smeared" over the entire element area. Isotropy is assumed prior to cracking with orthotropic behaviour after crack formation. The total strain is decomposed into two components, the strain in the uncracked material and the strain in the crack. The uncracked material and the crack are assumed to work in series. Additionally the crack orientation is assumed to remain fixed according to the smeared-fixed crack concept. The axes of orthotropy therefore remain normal and parallel to the crack surface.

\subsection{Analytical formulation}

The complete derivation of the material model can be found in [3]. Only the fundamental modelling aspects are reported here.

The crack tangent stiffness matrix takes the form:

$$
D^{c r}=\left[\begin{array}{cc}
D^{I} & 0 \\
0 & D^{I I}
\end{array}\right]
$$

Where $D^{I}$ and $D^{I I}$ are the Mode I and II stiffness moduli respectively. The assumption of zero off-diagonal terms implies that direct shear-normal coupling is ignored. This effect is instead obtained indirectly, by relating the shear modulus $D^{I I}$ to the crack normal strain. The effect of this simplification is discussed in the analysis output and conclusions.

\subsubsection{Mode I parameters}

A simple Rankine-type tension-cut off condition is assumed in the principal stress space. Only one strength parameter, namely the uniaxial tensile strength $f_{c t}$ is therefore needed to represent this model.

Fracture propagation parameters include the fracture energy $G_{f t}$ and the shape of the softening diagram, which is assumed to be exponential. The local Mode I crack traction-strain $\left(t_{1}^{c r}-\varepsilon_{1}^{c r}\right)$ relation has the form (where $h$ is the crack band width [9]):

$$
t_{1}^{c r}=f_{c t} e^{-\frac{f_{c t} h}{G_{f t}} \varepsilon_{1}^{c r}}
$$

The crack tangent stiffness is the derivate of the softening function and is therefore also expressed in terms of the strength and energy parameters, as well as the shape of the softening diagram.

$$
D^{I}=\frac{d}{d \varepsilon_{1}^{c r}}\left(t_{1}^{c r}\right)=\frac{-f_{c t}{ }^{2} h}{G_{f t}} e^{-\frac{f_{c t} h}{G_{f t}} \varepsilon_{1}^{c r}}
$$

Linear unloading and reloading in Mode $\mathrm{I}$ is accounted for by the model [3], but is not discussed here. 


\subsubsection{Mode II parameters}

The Mode II response has a limit function of the same type as for Mode I, namely

$$
t_{12}^{c r}=f_{C S} e^{-\frac{f_{c s} h}{G_{f s}} \gamma_{12}^{c r}}
$$

The shear stiffness for initial Mode II loading as well as unloading and reloading is a function of the normal strain in the crack $(E q .5)$. The crack width therefore determines the initial shear stiffness and hence the peak shear stress reached. Loading along the limit function is a function of shear strain only (Eq.4). Stated differently, the crack shear stress is a function of the crack normal and shear strain during loading and unloading. Once the Mode II limit function is reached, the shear stress and tangent stiffness is only a function of the crack shear strain (Eq.4).

$$
D^{I I}=\max \left(\left[1-\frac{\varepsilon_{1}^{c r} h}{w_{m}}\right] G \cdot f_{i}, G_{\min }\right) \cdot h
$$

Where $t_{12}^{c r}=$ crack shear traction, $\gamma_{12}^{c r}=$ crack shear strain; $f_{c s}=$ peak shear stress on limit function (where $\left.\varepsilon_{1}^{c r}=0, \gamma_{12}^{c r}=0\right) ; G_{f s}=$ shear fracture energy; $w_{m}=$ calibrated model parameter; $G=$ elastic shear modulus; $f_{i}$ = calibrated model parameter; $G_{\min }=$ minimum shear modulus

\subsection{Numerical procedure}

User subroutine UMAT is called for each integration point at each iteration of every increment. It is provided with the material state at the start of the increment (stress, solution-dependent state variables, temperature, and any predefined field variables) and with the increments in temperature, predefined state variables, strain, and time. The complete procedure and FORTRAN code can be found in [3].

\subsection{Model calibration}

\subsubsection{Calibration of Mode I model}

Two material parameters are required for the Mode I material model: peak tensile strength $f_{c t}$ and Mode I fracture energy $G_{f t}$. Parameter values as obtained from the composite-scale experimental investigation in Section 2, are given in Table 3. Fig.13 plots the calibrated model (Eq.2) with the sample and average uniaxial tensile response for SCC $V_{f}=0.75 \%$.

Table 3. Mode I material parameter values

\begin{tabular}{lcccccc}
\hline Composite: & & SCM & & & SCC \\
\hline$V_{f}[\%]$ & $0.5 \%$ & $0.75 \%$ & $1.0 \%$ & $0.5 \%$ & $0.75 \%$ & $1.0 \%$ \\
\hline$f_{c t}\left[\mathrm{~N} / \mathrm{mm}^{2}\right]$ & 2.85 & 2.99 & 2.61 & 4.40 & 3.40 & 3.65 \\
\hline$G_{f t}[\mathrm{~N} / \mathrm{mm}]$ & 3.23 & 3.79 & 3.51 & 2.11 & 2.75 & 3.55 \\
\hline
\end{tabular}

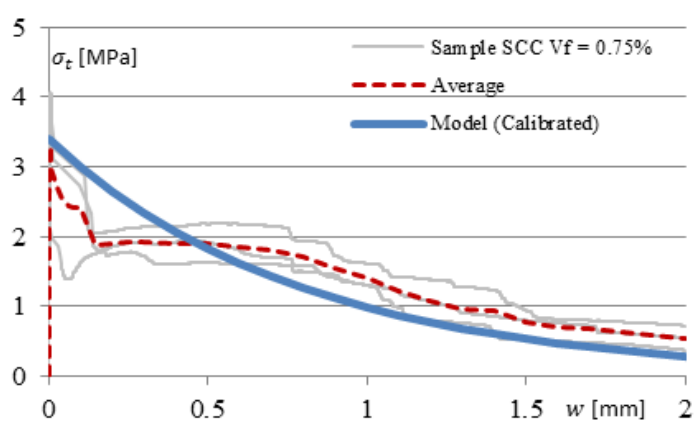

Fig. 13. Typical uniaxial tension stress $\sigma_{t}[\mathrm{MPa}]$ vs crack width $w[\mathrm{~mm}]$

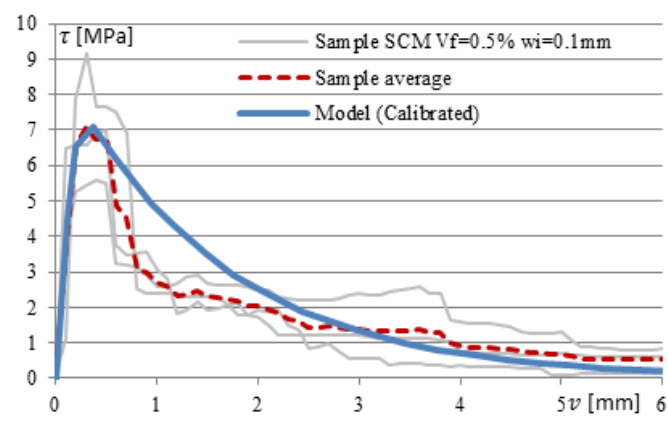

Fig. 14. Typical shear stress $\tau[\mathrm{MPa}]$ vs. shear displacement $v$ [mm]

\subsubsection{Calibration of Mode II model}

Four parameters are used to define and calibrate the Mode II material model. The parameter values are given in Table 4 for each composite type, fibre dosage and precrack value. The shear fracture energy $\left(G_{f s}\right)$ is the average experimental value as determined in the previous Section 3. The calibrated model parameters include $f_{c s}, w_{m}$ and $f_{i}$, adjusted to fit the experimental average data. The model is compared to the sample and average data in Fig. 14 for SCM $V_{f}=0.5 \% w_{i}=0.1 \mathrm{~mm}$.

\subsection{Model verification}

The Iosipescu shear test specimen as illustrated in Fig.8a is modelled in Abaqus. Model details including dimensioning, boundary conditions, mesh and analysis details can be found in [3]. Two boundary conditions are considered for the inner supports: BC1 - both inner supports restrained against horizontal translation and $\mathrm{BC} 2$ - only one inner support is restrained against horizontal translation. In the case of $\mathrm{BC} 1$, the model overestimates the crack opening, whereas $\mathrm{BC} 2$ has a closer resemblance to the experimental deformation. However problems arise when using $\mathrm{BC} 2$ with a material model where Mode I and II are decoupled and dilatancy is not accounted for by the material model. This is discussed further in terms of the stress output.

There is a discrepancy between the calibrated model and Abaqus shear stress S12 in the computation of the initial shear stiffness and peak shear stress (Fig.15). Recall that the initial shear stiffness is a function of the crack width, which is overestimated by the Abaqus model for BC1. 
Table 4. Mode II material and model parameter values

\begin{tabular}{ccccccc}
\hline Comp. & $\mathrm{V}_{\mathrm{f}}$ & $\mathrm{W}_{\mathrm{i}}$ & $\mathrm{f}_{\mathrm{cs}}$ & $\mathrm{G}_{\mathrm{fs}}$ & $\mathrm{W}_{\mathrm{m}}$ & $\mathrm{f}_{\mathrm{i}}$ \\
\hline & $\%$ & $\mathrm{~mm}$ & $\mathrm{~N} / \mathrm{mm}^{2}$ & $\mathrm{~N} / \mathrm{mm}$ & $\mathrm{mm}$ & - \\
\hline \multirow{3}{*}{$\mathrm{SCM}$} & \multirow{2}{*}{0.5} & 0.1 & 9.0 & 14.12 & 0.50 & 0.005 \\
& & 0.3 & 4.0 & 10.90 & 0.48 & 0.018 \\
& \multirow{2}{*}{1.0} & 0.1 & 9.5 & 13.95 & 0.60 & 0.007 \\
& & 0.3 & 6.0 & 12.47 & 0.55 & 0.006 \\
& \multirow{2}{*}{0.5} & 0.3 & 10.0 & 16.10 & 0.50 & 0.007 \\
& & 0.1 & 7.0 & 21.74 & 0.65 & 0.006 \\
\hline \multirow{2}{*}{ SCC- } & \multirow{2}{*}{0.75} & 0.1 & 8.3 & 7.94 & 0.60 & 0.007 \\
& & 0.3 & 7.2 & 18.78 & 0.65 & 0.0035 \\
& \multirow{2}{*}{1.0} & 0.1 & 12.2 & 25.91 & 0.52 & 0.00065 \\
& & 0.3 & 10.2 & 24.06 & 0.60 & 0.015 \\
\hline SCC- & \multirow{2}{*}{0.5} & 0.1 & 6.0 & 14.64 & 0.55 & 0.006 \\
600 & & 0.3 & 6.0 & 13.84 & 0.56 & 0.014 \\
\hline
\end{tabular}

Fig. 16 compares $\mathrm{BC} 1$ and $\mathrm{BC} 2$ for one composite. $\mathrm{BC} 2$ better approximates peak shear stress, but at large shear displacements, shear stress increases again and deviates from the material model. This behaviour is characterised by Rots [10] as "stress-locking", which occurs in continuum and smeared crack modelling when fixed cracks with significant shear retention lead to stress rebuild. For $\mathrm{BC} 2$ the normal strain and stress parallel to the crack becomes unrealistically high. The stiffness parallel to the crack is a function of crack width, which becomes negative during the shear step for $\mathrm{BC} 2$, and is therefore not reliable.

\subsection{Empirical link between composite and single fibre scale}

An empirical model utilises the data obtained at the single fibre and composite-scale, as well as an analysis

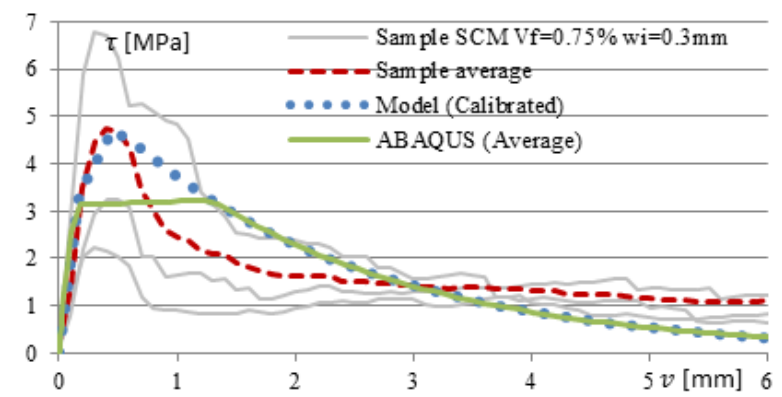

Fig. 15. Typical shear stress $\tau$ vs. shear displacement $v$

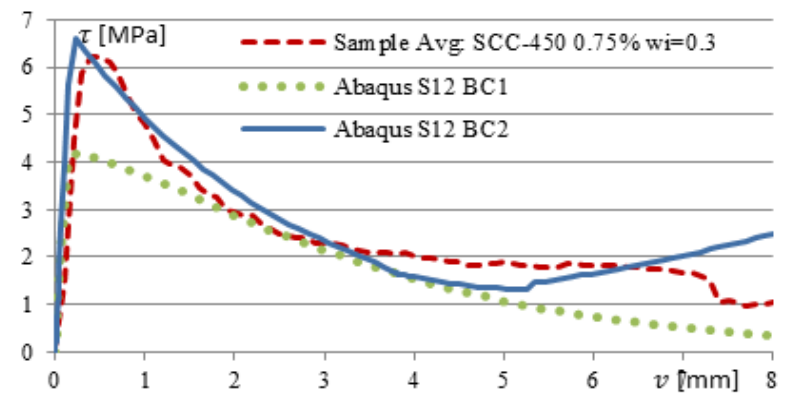

Fig. 16. Typical shear stress $\tau$ vs. shear displacement $v$ for BC1 and $\mathrm{BC} 2$ of the fibre distribution to simulate the fibre component of the composite Mode II response.

\subsubsection{Model description and input}

Given the total fibre count and fibre orientation distribution (Fig.10), the number of fibres that fall inside a defined orientation interval can be determined. The average transverse pull-out load vs. normal displacement response (Fig.12b) for each fibre orientation is multiplied by the number of fibres in each corresponding orientation interval and added together to estimate the total fibre contribution to the composite response (Only data for $L_{f} / 4$ is used here). Finally, for each composite and fibre volume fraction, the average shear displacement vs. crack width relation at the composite scale is used to estimate the shear load vs. shear displacement relation.

\subsubsection{Model verification}

Fig.17 shows a typical comparison of the empirical model to the experimental composite response. Peak shear load: In general, a better approximation is made for an initial crack width, $w_{i} \approx 0.3 \mathrm{~mm}$. Recall that the model only considers the fibre component. It is therefore postulated that at smaller initial crack width, $w_{i} \approx 0.1$ $\mathrm{mm}$, shear interface cohesion and roughness/friction is still present, contributing to peak shear load. As the crack width, $w_{c}$ increases, the model closely simulates the composite response, as the majority of the shear interface cohesion and friction is no longer present. Only the fibre mechanism provides resistance at this stage.

Residual/tail end response: Model and experiment compare well. Initial stiffness: The model does not simulate the initial stiffness before and up to peak shear load. The stiffness is underestimated and in most cases, the modelled peak shear load is offset from the actual peak shear load with a significant margin. This is however to be expected for a model that only simulates the fibre component and does not account for the composite stiffness provided by the shear interface cohesion and shear interface roughness or aggregate interlock. The empirical 'fibre-only' model can be improved with a larger sample size at the single fibre and composite-scale. The fibre pull-out response should also be investigated for other fibre orientations and embedment lengths. With respect to the fibre distribution (fibre count and orientation distribution) determined via CT-scanning, a larger sample size is also recommended.

\subsection{Summary and conclusions}

The numerical and empirical models developed simulate the composite response well, given their relative simplicity and limited experimental data. Limitations are however encountered for continuum elements and this particular application due to unstable/unreliable results at larger shear-slip (observed for BC2). This behaviour is 


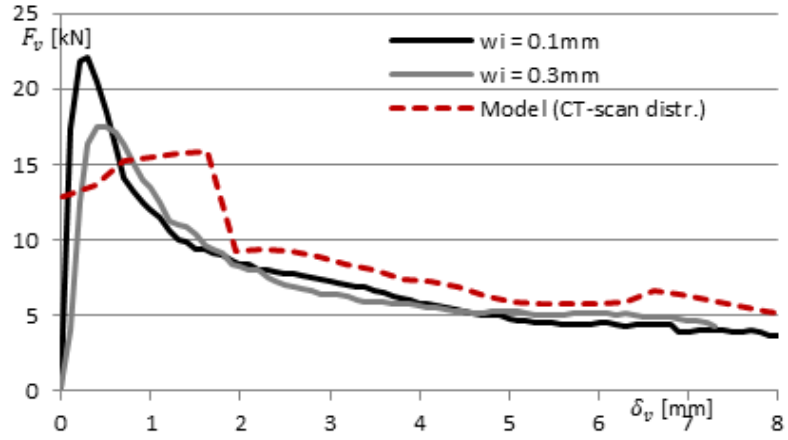

Fig. 17. Shear load $\left(F_{v}\right)$ vs. shear displacement $\left(\delta_{v}\right)$ for SCC$4500.75 \%$

mitigated in this instance by choosing different boundary conditions (BC1). Future research should attempt to link the Mode I and Mode II response and account for dilatancy and confinement across the shear interface.

\section{Conclusions}

This research provides insight into experimental design for the fundamental fracture modes of SFRC. A contribution is made to the limited literature available on the link between the single fibre transverse pull-out response and the composite Mode II fracture behaviour. The numerical and empirical models developed simulate the composite response well, given their relative simplicity and limited experimental data. The constitutive model and numerical procedure should aid in material design and provide a foundation for defining material laws.

\section{References}

1. T. Soetens, S. Matthys, BEFIB2012 (2012)

2. G. Lee, S. Foster, UNICIV Report R-444 (2006)

3. S. Zeranka, Steel-Fibre Reinforced Concrete: Multiscale Characterisation towards Numerical Modelling, PhD-thesis, Stellenbosch University (2017)

4. Bekaert Dramix, www.bekaert.com

5. N. Iosipescu, J. Materials, 2(3), 537 (1967)

6. T. Arakawa, K. Ohno, Architectural Institute of Japan, 57, 581(1957)

7. Abaqus 6.10 Finite Element Analysis software, SIMULIA $^{\mathrm{TM}}$ by Dassault Systèmes ${ }^{\circledR}$

8. Y. Rashid, Nuc. Eng. \& Design, 7(4), 334 (1968)

9. Z. Bazant, B. Oh, Mat. \& Constr., 16(3), 155 (1983)

10. J. Rots, ICF7, (1989) 